\title{
25 Research Square \\ Soft Tissue Profile Changes in Patients With Class II malocclusion
}

Jovana Milutinovic ( $D$ jovanamilutinovic2005@yahoo.com )

University of Belgrade

Zorana Stamenkovic

University of Belgrade

Ksenija Zelic

University of Belgrade

Nemanja Marinkovic

University of Belgrade

Nenad Nedeljkovic

University of Belgrade

\section{Research Article}

Keywords: facial esthetics, Class II malocclusion, profile changes.

Posted Date: February 11th, 2021

DOI: https://doi.org/10.21203/rs.3.rs-154363/v1

License: (c) (i) This work is licensed under a Creative Commons Attribution 4.0 International License.

Read Full License 


\section{Abstract}

\section{Background}

The objective of this study was to identify the soft tissue profile outcomes of orthodontic treatment of Class II, division 1 malocclusion patients and to determine if these changes are related with different treatment protocol.

\section{Methods}

The sample of this study consisted of 50 Caucasian patients [ 22 males; 28 females], with a mean age of 15.8 years. The sample was divided in two groups (both groups treated with multibracket therapy): first group was non-extraction group [25 patients] treated first with the Herbst appliance, and second group was four premolars extraction group [25 patients] treated with a multibracket appliance. The patients' preand post-treatment profile photographs were used, and the soft tissue landmarks were identified. Afterwards, the angular parameters were determined on each photo. Paired-sample t-test was used for intragroup comparisons. For testing the differences in all parameter values between groups, two-sample $t$ test was used.

\section{Results}

The improvement in the non-extraction group was evident in the decrease of the nasomental angle $[P=0.02]$, the angle representing the projection of the upper lip to the chin $[P=0.01]$, as well as the upper lip angle $[P=0.01]$. On the other hand, the nasolabial angle increased significantly $[P=0.01]$, as well as the mentolabial angle $[\mathrm{P}=0.02]$. In the extraction group, the nasolabial angle showed a significant increase $[P=0.03]$. Two soft tissue variables showed significant differences between the groups: the total facial angle or facial convexity including the nose $[\mathrm{P}=0.04]$ and the angle presenting the projection of the upper lip to chin $[\mathrm{P}=0.01]$.

\section{Conclusions}

The patients treated without extractions showed a significant improvement of the convex profile and favorable soft tissue changes in the lower third of the face. The orthodontic treatment of Class II, division 1 malocclusions induce positive effects on the soft tissue facial profile, which depends on different treatment protocols.

\section{Background}

The improvement of facial features is the patient's main aspiration when starting an orthodontic treatment, and thus of primary importance for clinicians. An attractive facial appearance affects social acceptance and psychological well-being, which has a profound effect on a person's self-esteem and social adjustment ability [1]. Soft tissue of the face, together with the underlying dentoskeletal tissues, determines the facial features of a person [2]. Orthodontists, maxillofacial and plastic surgeons are 
expected to achieve not only functional, but also esthetic goals for their patients, both equally important [3].

The class II, division 1 malocclusion results in disbalanced facial harmony, primarily noticeable in the profile and the lower facial third. Previous studies showed that the convex profile, which is typical for this type of malocclusion, is one of the least desirable features of the face [4]. These patients are unsatisfied with their smile and facial look, especially in their teenage years, since they are often being perceived by peers as unattractive. As self-esteem is strongly influenced by facial appearance, solving this problem is of primary importance in achieving aesthetic treatment goals. Therefore, improvement of facial appearance in teenage patients could improve their quality of life through their most vulnerable years [4, 5].

The treatment of Class II, division 1 malocclusion depends on the age of the patient, growth potential, severity of malocclusion and skeletal discrepancy, but also on the compliance of the patient. Orthodontists should comprehensively understand the importance of developing an individualized treatment plan, adjusted to the patient's specific dental and skeletal problems, needs and desires. This type of malocclusion can be treated with functional or fixed functional appliances combined with the multibracket appliance, with or without extractions. Small skeletal discrepancies may only need multibracket therapy for the correction of existing malocclusion and teeth alignment [6]. On the other hand, more severe skeletal discrepancies may require an orthognathic surgical treatment to modify the position and length of skeletal structures, to obtain better esthetic results [7]. Despite the numerous studies conducted on the consequences of extractions, it is still a question of debate among orthodontists. Some investigators reported flattening of the soft tissue profile after extraction treatment, while others claim no such effect [8-11].

Aside from skeletal evaluation, orthodontic diagnosis and treatment planning should include facial soft tissue analysis which has a relevant role in achieving a good facial balance. Therefore, it is of high importance to assess the effects of both dental and skeletal changes on the soft tissue profile by the clinicians [2].

Although cephalometric analysis is one of the most common part of diagnosis and treatment planning among orthodontists, the validity of cephalometric measurements has been questioned [3]. Several authors proposed lateral photographs for the aesthetic facial profile evaluation [12-14].

This study, therefore, aimed to identify the soft tissue profile outcomes of the orthodontic treatment of Class II, division 1 malocclusion. A further aim was to determine if soft tissue profile changes are connected with different treatment protocols. The hypothesis underlying this investigation is that orthodontic treatment of Class II, division 1 malocclusion changes the soft tissue profile, and moreover, that those changes depend on different treatment protocols.

\section{Methods}


The sample for this study consisted of 50 Caucasian patients (22 males; 28 females), with a mean age of $15.8 \pm 1.4$ years, treated at the University of Belgrade, School of Dental Medicine, Clinic for Orthodontics between 2014 and 2018. This retrospective study was approved by the Ethical Committee of the Belgrade University (Protocol number: 46/15) and informed consent was obtained from the patient's parents/guardians. All subjects were selected according to the following inclusion criteria (pretreatment): full permanent dentition (excluded third molars), Class II molar occlusion, division 1 (with characteristic convex profile, deep mentolabial sulcus, retruded chin, and reverted lower lip), overjet more than $7 \mathrm{~mm}$, moderate irregularity of anterior crowding according to the Little`s Irregularity Index [15], and postpubertal stage of skeletal maturity (CS6) [16]. Exclusion criteria included patients with a systemic disease, craniofacial anomalies, patients with impacted teeth and poorly visible cephalograms. After successful orthodontic treatment, all the patients achieved the Class I occlusion, and received a vacuumformed retainer on a same day as appliance removal.

The subjects were divided in two study groups:

1. First group consisted of 25 patients treated with the combined two-phase therapy. First phase included the cast splint Herbst appliance type I for average period of seven months. Afterwards, each patient underwent a standardized non-extractive treatment protocol. The treatment duration was on average 20 months, respectively. The skeletal and dentoalveolar changes in this group of patients are visible with superimposition in Fig. 1.

2. Second group consisted of 25 patients treated with four premolars extractive treatment protocol, followed with Class II intermaxillary elastic. The treatment duration was on average 19 months, respectively. The skeletal and dentoalveolar changes in this group of patients are visible with superimposition in Fig. 2.

The patients' pre-treatment and post-treatment profile photographs were used [4]. The right-side profile photographs were taken in a standing position, in central occlusion. The subjects' Francfort horizontal plane was kept as parallel to the floor as possible during the taking of the photographs. Before every recording, the operator ensured that the subject's forehead, neck, and ear were clearly visible [6]. The photographs were then printed, and the soft tissue landmarks were identified. The landmarks used in this investigation were: glabella $(\mathrm{G})$, nasion $(\mathrm{N})$, nasal dorsum $(\mathrm{Nd})$, pronasale (Prn), columella $(\mathrm{Cm})$, subnasale $(\mathrm{Sn})$, labiale superior $(\mathrm{Ls})$, labiale inferior $(\mathrm{Li})$, supramentale $(\mathrm{Sm})$, pogonion $(\mathrm{Pg})[10]$. Afterwards, the angular parameters were determined on each photo and used in evaluating soft tissue profile changes. The photogrammetric analysis was based on comparing values of parameters changes before and after the treatment, regardless of average values for these parameters, respectively. These measurements are illustrated in Fig. 3. Table 1 provides the definition of angular measurements used in the study. The whole sample was measured by one researcher (JM) and once again after two months. Also, all measurements were performed by the second researcher $(\mathrm{NN})$. This was done to evaluate intra and inter observer reliability. Radiographic analyses rely on skeletal and dental measurement, whereas 
soft tissue facial measurements are less emphasized. Therefore, for providing a complete overview of changes during and after orthodontic treatment, photogrammetric analysis has been used.

Table 1

Definitions of angular measurements.

\begin{tabular}{|ll|}
\hline Angular measurement & Definition \\
\hline $\mathrm{N}-\mathrm{Prn}-\mathrm{Pg}\left(^{\circ}\right)$ & Nasomental angle \\
$\mathrm{N}-\mathrm{Prn}-\mathrm{Cm}\left(^{\circ}\right)$ & Nose tip angle \\
$\mathrm{Cm}-\mathrm{Sn}-\mathrm{Ls}\left(^{\circ}\right)$ & Nasolabial angle \\
$\mathrm{Li}-\mathrm{Sm}-\mathrm{Pg}\left(^{\circ}\right)$ & Mentolabial angle \\
$\mathrm{G}-\mathrm{N}-\mathrm{Nd}\left(^{\circ}\right)$ & Nasofrontal angle \\
$\mathrm{N}-\mathrm{Prn}-\mathrm{Pg}\left(^{\circ}\right)$ & Total facial angle or facial convexity including the nose \\
$\mathrm{G}-\mathrm{Sn}-\mathrm{Pg}\left(^{\circ}\right)$ & Facial angle or angle of facial convexity excluding the nose \\
$\mathrm{N}-\mathrm{Pg}-\mathrm{Ls}\left(^{\circ}\right)$ & Projection of the upper lip to chin \\
$\mathrm{Sn}-\mathrm{Ls}-\mathrm{Pg}\left(^{\circ}\right)$ & Upper lip angle \\
$\mathrm{N}-\mathrm{Pg}-\mathrm{Li}\left(^{\circ}\right)$ & Projection of the lower lip to chin \\
\hline
\end{tabular}

\section{Statistical analysis}

The collected data were subjected to statistical analysis using SPS software (SPSS, IBM Corp. Version 17.0 for Windows, Chicago, IL). The Kolmogorov-Smirnov test was applied to test whether the data distribution fits the probability density function also known as Gaussian function or bell curve. Subsequently, if the test had not rejected the assumed normal distribution, the parametric tests would have been used. Paired-sample t-test was used for intragroup comparisons. For testing the differences in all parameter values between groups, two-sample t test was used. In all analyses, the significance level was set at 0.05 . The Kolmogorov-Smirnov test showed normality of distribution of the obtained data in both groups. In order to evaluate intra and inter-observer reliability, intra-class correlation coefficient (ICC) was calculated.

\section{Results}

Intra and inter-observer agreement was found to be excellent (ICC $=0.983$ for intra-observer, ICC $=0.974$ inter-observer agreement). Angular measurements in the first group treated with the Herbst appliance and without extractions are demonstrated in Table 2 . Several statistically significant profile changes could be observed. The nasomental angle ( $\mathrm{N}-\mathrm{Prn}-\mathrm{Pg})$ decreased significantly

$(\overline{\mathrm{x}}=-1 \pm 1.0 ; \mathrm{P}=0.02)$; furthermore, the angle representing projection of the upper lip to chin $(\mathrm{N}-\mathrm{Pg}-\mathrm{Ls})$ showed significant decrease $(\bar{x}=-2.11 \pm 2.04 ; P=0.01)$. The Upper lip angle showed a large decrease 
significantly $(\overline{\mathrm{x}}=-4.94 \pm 10.1 ; \mathrm{P}=0.01)$ over time in the non-extraction group of patients. On the other hand, the nasolabial angle (Cm-Sn-Ls) increased significantly in this group of patients $(\overline{\mathrm{x}}=+1.33 \pm 2.81$; $\mathrm{P}=0.01)$. Moreover, the mentolabial angle $(\mathrm{Li}-\mathrm{Sm}-\mathrm{Pg})$ showed a significant large increase $(\overline{\mathrm{x}}=+12.68 \pm$ $12.57 ; P=0.02)$.

Table 2

Descriptive statistics of the variables in Herbst/non-extraction group.

\begin{tabular}{|lllll|}
\hline \multicolumn{4}{|c|}{ Herbst/Non-Extraction Treatment Protocol } & \\
\hline & Before & After & Difference & \\
\hline Variable & Mean \pm SD & Mean \pm SD & Mean \pm SD & P-value change over time \\
\hline N-Prn-Pg & $35.93 \pm 2.69$ & $34.93 \pm 2.81$ & $-1 \pm 1.01$ & $0.02^{*}$ \\
\hline N-Prn-Cm & $80.37 \pm 5.61$ & $78.93 \pm 6.1$ & $-1.44 \pm 0.19$ & 0.41 \\
\hline Cm-Sn-Ls & $107 \pm 6.64$ & $108.33 \pm 9.88$ & $1.33 \pm 2.81$ & $0.01^{*}$ \\
\hline Li-Sm-Pg & $107.06 \pm 15.65$ & $119.74 \pm 20.16$ & $12.68 \pm 12.57$ & $0.02^{*}$ \\
\hline G-N-Nd & $141.54 \pm 7.38$ & $140.43 \pm 6.84$ & $-1.11 \pm 0.19$ & 0.08 \\
\hline N-Prn-Pg & $121.8 \pm 3.91$ & $124.17 \pm 7.3$ & $2.37 \pm 0.95$ & 0.18 \\
\hline G-Sn-Pg & $159.56 \pm 5.55$ & $163.41 \pm 7.07$ & $3.85 \pm 4.43$ & 0.05 \\
\hline N-Pg-Ls & $10.46 \pm 1.46$ & $8.35 \pm 2.54$ & $-2.11 \pm 2.04$ & $0.01^{*}$ \\
\hline Sn-Ls-Pg & $21.33 \pm 5.17$ & $16.39 \pm 5.77$ & $-4.94 \pm 10.1$ & $0.01^{*}$ \\
\hline N-Pg-Li & $4.15 \pm 2.33$ & $6.59 \pm 10.75$ & $2.44 \pm 1.3$ & 0.29 \\
\hline Significant differences at *P $<0.05$. & & \\
\hline
\end{tabular}

Changes in soft tissue profile variables in the extraction group of patients are presented in Table 3 . This group showed a greater significant increase in nasolabial angle $(C m-S n-L s)(\bar{x}=+3.96 \pm 4.43 ; P=0.03)$. However, no significant differences were detected in other soft tissue variables. 
Table 3

Descriptive statistics of the variables in the extraction group.

\section{Extraction Treatment Protocol}

\begin{tabular}{|lllll|}
\hline & Before & After & Difference & \\
\hline Variable & Mean \pm SD & Mean \pm SD & Mean \pm SD & P-value change over time \\
\hline N-Prn-Pg & $35.68 \pm 3.01$ & $36.3 \pm 2.94$ & $0.62 \pm 3.73$ & 0.21 \\
\hline N-Prn-Cm & $78.62 \pm 6.5$ & $79.92 \pm 7.97$ & $1.3 \pm 3.44$ & 0.56 \\
\hline Cm-Sn-Ls & $103.26 \pm 7.39$ & $107.22 \pm 10.16$ & $3.96 \pm 4.43$ & $0.03^{*}$ \\
\hline Li-Sm-Pg & $112.18 \pm 24.18$ & $119.92 \pm 15.86$ & $7.74 \pm 2.89$ & 0.33 \\
\hline G-N-Nd & $138.04 \pm 6.79$ & $136.28 \pm 9.18$ & $-1.76 \pm 2.04$ & 0.29 \\
\hline N-Prn-Pg & $123.96 \pm 6.2$ & $124.76 \pm 7.58$ & $0.8 \pm 2.1$ & 0.29 \\
\hline G-Sn-Pg & $162.88 \pm 6.45$ & $163.3 \pm 3.92$ & $0.42 \pm 1.61$ & 0.52 \\
\hline N-Pg-Ls & $9.94 \pm 3.32$ & $8.96 \pm 1.88$ & $-0.98 \pm 1.01$ & 0.07 \\
\hline Sn-Ls-Pg & $20.24 \pm 4.65$ & $18.38 \pm 3.46$ & $-1.86 \pm 1.72$ & 0.06 \\
\hline N-Pg-Li & $4.62 \pm 1.71$ & $5.36 \pm 2.07$ & $0.74 \pm 1.47$ & 0.08 \\
\hline Significant differences at *P<0.05. & & \\
\hline
\end{tabular}

Table 4 describes intergroup comparisons of the soft tissue variables. Only two soft tissue variables showed significant differences between two groups: total facial angle or facial convexity including the nose $(\mathrm{N}-\mathrm{Prn}-\mathrm{Pg})$ increased significantly $(\overline{\mathrm{x}}=-2.09 \pm 1.1 ; \mathrm{P}=0.04)$. As for the angle presenting projection of the upper lip to chin $(\mathrm{N}-\mathrm{Pg}-\mathrm{Ls})$, its value showed significant decrease $(\overline{\mathrm{x}}=+0.65 \pm 3.73 ; \mathrm{P}=0.01)$. 
Table 4

Descriptive statistics of the variables comparing both treatment groups.

\begin{tabular}{|lllll|}
\hline \multicolumn{4}{|c|}{ Herbst/Non-Extraction Versus Extraction Treatment Protocol } \\
\hline & Before & After & Difference & \\
\hline Variable & Mean \pm SD & Mean \pm SD & Mean \pm SD & P-value change over time \\
\hline N-Prn-Pg & $-1.04 \pm 3.08$ & $1.04 \pm 2.25$ & $2.08 \pm 2.92$ & 0.33 \\
\hline N-Prn-Cm & $-1.08 \pm 5.89$ & $1.23 \pm 4.3$ & $2.31 \pm 2.81$ & 0.71 \\
\hline Cm-Sn-Ls & $-3.52 \pm 7.04$ & $-1.45 \pm 8.26$ & $2.07 \pm 3.71$ & 0.34 \\
\hline Li-Sm-Pg & $-8.39 \pm 17.35$ & $-11.95 \pm 21.54$ & $-3.56 \pm 7.32$ & 0.61 \\
\hline G-N-Nd & $0.96 \pm 6.69$ & $1.34 \pm 4.45$ & $0.38 \pm 1.46$ & 0.51 \\
\hline N-Prn-Pg & $-0.52 \pm 5.18$ & $-2.61 \pm 5.84$ & $-2.09 \pm 1.1$ & $0.04^{\star}$ \\
\hline G-Sn-Pg & $-0.78 \pm 5.69$ & $-3.89 \pm 4.61$ & $-3.11 \pm 2.29$ & 0.05 \\
\hline N-Pg-Ls & $1.46 \pm 2.2$ & $2.11 \pm 2.25$ & $0.65 \pm 3.73$ & $0.01 *$ \\
\hline Sn-Ls-Pg & $1.78 \pm 4.77$ & $5.09 \pm 5$ & $3.31 \pm 0.24$ & 0.11 \\
\hline N-Pg-Li & $-0.72 \pm 1.14$ & $-2.66 \pm 10.39$ & $-1.94 \pm 2.04$ & 0.15 \\
\hline Significant differences at *P $<0.05$. & & \\
\hline
\end{tabular}

\section{Discussion}

The success of orthodontic treatment is closely related to facial appearance improvement. A balanced soft tissue profile is an important factor to achieve during orthodontic treatment [2]. This type of malocclusion is frequently reported as the irregularity that alters facial proportions, symmetry, and balance. Thus, correction of facial features will lead not only to facial profile correction, but also to longterm psychosocial well-being of patients [5]. Orthodontic treatment modifies the position, length, and relation between skeletal and dentoalveolar structures, and subsequently, facial expressions and esthetics are modified and enhanced (these effects are shown in Figs. 1 and 2). Facial harmony can often be described as dependent on morphological relations, and proportions between three facial structures: nose, lips, and chin [17]. The facial profile consists of five facial prominences: the forehead, nose, lips, chin, and submental-cervical region. The interrelationship between these various components of the facial profile plays an important role in the perception of facial esthetics [18]. Relations between these structures are presented using angular measurements in the photogrammetric analysis in this investigation.

The nasomental angle (N-Prn-Pg), or nasal prominence angle, is in the range between 20 and 30 degrees in Class I patients [19], whereas in Class II Patients, the value is increased. In this study, the nasomental 
angle showed a statistically significant decrease in the non-extraction group of patients, although it was not clinically relevant $\left(-1^{\circ}\right)$. This favorable outcome could have occurred as a result of anterior movement of the soft tissue point pogonion $(\mathrm{Pg})$. This movement promoted positive changes on the soft tissue profile and was reported also by doRego et al. [20].

Significant improvements in facial profile were recorded in the first group of patients (treated with the Herbst appliance without extractions). In particular, the nasolabial (Cm-Sn-Ls) and mentolabial (Li-Sm$\mathrm{Pg}$ ) angles showed significant increase after the treatment. The nasolabial angle ( $\mathrm{Cm}-\mathrm{Sn}$-Ls) can be changed with both orthodontic and surgical treatment. It plays an important role in a facial profile appearance, and in some cases, it can be used as a guideline for the extraction decision. According to a study by Bergman [21], regardless of the type of treatment needed for the patients (whether it is surgical or orthodontic correction), this angle should be $102 \pm 8$ degrees. After orthodontic treatment, this angle increased significantly, since the upper lip moved backwards and downwards, and its prominence has been decreased, mostly due to retrusion of the upper incisors. The nasolabial angle also showed a significant increase in the second group of patients, treated with premolar extractions. The increase of this angle was reported also by lared et al. [22] who confirmed that a backward movement of the upper lip occurred because of orthodontic treatment with extraction of premolars.

The mentolabial angle ( $\mathrm{Li}-\mathrm{Sm}-\mathrm{Pg})$ also showed great variability. A more pronounced mentolabial angle can be seen in Class II and vertical maxillary deficiency cases. In both groups of patients, this angle has been increased after the treatment, as a result of achieving a balanced dentoalveolar relation, due to upper incisors retrusion [23].

Significant improvements in facial profile concerning chin and upper lip balance were recorded in the first group of patients. In particular, the angle determining the projection of the upper lip to the chin (N-Pg-Ls), as well as the upper lip angle $(\mathrm{Sn}-\mathrm{Ls}-\mathrm{Pg})$, showed a significant reduction. This result is related to a less pronounced upper lip. The value of these angles showed a statistical significance in the non-extraction group, given the fact that point Pg moved forward, while point Ls moved backward, which is an expected result of treatment with the Herbst appliance [24]. Moreover, this is also a result of decreasing of the upper lip prominence, as a consequence of upper incisors retrusion, in a ratio of 1:3. Many authors confirmed the relation between upper lip position and upper incisors retrusion, in the ratio of 1:3 $[25,26]$. Furthermore, esthetical modification depends on upper and lower incisors position, as well as on the change of the position and development of the lower jaw [27].

The angle N-Pg-Ls showed a statistically significant difference comparing the two groups of patients. The lower lip is the adjacent esthetic subunit to the chin, and its features play an important role in determining facial esthetics in the lower third of the face [28]. As such, the prominence of the lower lip may influence the perception of chin prominence and thus the overall management plan in terms of camouflage vs orthognathic surgery and extraction vs non-extraction decisions $[22,29,30]$.

Therefore, a change in the lower lip position and consequent change in the lip/chin relation influences facial esthetics, as these entities determine the profile type. As mentioned, the facial profile in patients 
with this type of malocclusion is altered and considered unattractive before the treatment. As a result of improvement of these proportions and of the profile, the esthetic perception is changed from unattractive to attractive, which is one of the main reasons why patients seek orthodontic treatment [31].

The profile angles are used to assess convexity or concavity of the facial profile. The angle of facial convexity excluding the nose or facial angle (G-Sn-Pg) is supposed to be in a range of $165-175$ degrees [21]. This angle is decreased in Class II and increased in Class III. In our sample, all patients had a decreased value of this angle before the treatment. After the treatment, the facial angle was increased in both groups of patients, however, not significantly. The favorable outcome, not statistically significant, yet esthetically relevant, was the profile strengthening caused by reduction of facial convexity, which is previously one of the main reasons of patients' dissatisfaction [32].

Godt et al. [33] also described this angle as one of the most important in determining patient's skeletal class.

The angle of facial convexity including the nose or total facial angle (N-Prn-Pg) showed a statistically significant difference comparing the two groups of patients. This result can also be related to the previously mentioned effect of the Herbst appliance - forward movement of the point Pg [24].

It is of high importance to analyze the patients' profile before the treatment, in order to establish the most desirable treatment results. In some cases, there are limitations in treatment outcomes induced by facial features, their proportions and expressiveness (for instance, size and position of the chin and nose prior to treatment). Many authors compared different orthodontic treatments to establish if and how they influence the facial esthetics and overall appearance. Some of them found no statistical significance between different treatment protocols and improving the facial esthetics [22,30]. Nevertheless, many factors should be carefully evaluated before starting the orthodontic treatment [34]. At the end of the treatment, patients show satisfaction with their facial esthetic improvement, mostly judged by the influence of the environment and contemporary beauty canons.

\section{Conclusions}

Photogrammetric analysis is a simple and valid method to assess orthodontic treatment effects on the soft tissue profile. This study confirms previous reports on the improvement of the convex profile, and favorable soft tissue changes at the lower third of the face, after the orthodontic treatment of Class II division 1 malocclusions. Patients treated with the Herbst appliance without extractions presented better results in facial profile parameters than the group of patients treated with premolar extractions. This result is important for orthodontists treating patients with this type of malocclusion, as facial esthetics improvement is a key factor for determining treatment protocol and achieving patients'satisfaction.

\section{List Of Abbreviations}

$\mathrm{N}$ - nasion 


$$
\begin{aligned}
& \text { Prn - pronasal } \\
& \text { Pg - pogonion } \\
& \text { Cm - columella } \\
& \text { Sn - subnasale } \\
& \text { Ls - labial superior } \\
& \text { Li - labial inferior } \\
& \text { Sm - supramental } \\
& \text { G - glabella } \\
& \text { Nd - nasal dorsum } \\
& \text { Declarations }
\end{aligned}
$$

\section{Declarations}

\section{Ethics approval and consent to participate}

This study was approved by the Ethical Committee of the Belgrade University (number 46/15). All methods were carried out in accordance with relevant guidelines and regulations. The parents/guardians of every patient involved in this study have signed the consent to participate, which are available from the corresponding author on reasonable request.

\section{Consent for publication}

The parents/guardians of every patient involved in this study have signed the consent for publication, which are available from the corresponding author on reasonable request.

\section{Availability of data and materials}

The datasets used and/or analyzed during the current study are available from the corresponding author on reasonable request.

\section{Competing interest}

The authors declare that they have no competing interest.

\section{Funding}

This work was supported by the Ministry of Education, Science and Technological Development of the Republic of Serbia (Grant No. III41007). 


\section{Authors' contribution}

$\mathrm{JM}$ and $\mathrm{NN}$ analyzed and measured the parameters in photogrammetric analysis. ZS and NM analyzed and interpreted the patients' data. KZ made substantial contribution in writing the manuscript. All authors read and approved the final manuscript.

\section{Acknowledgements}

Not applicable.

\section{References}

1. Akter L, Hossain M. Angular photogrammetric soft tissue facial profile analysis of Bangladeshi young adults. APOS Trends Orthod. 2017; 7: 279-86.

2. Yu XN, Bai D, Feng X, Chen WJ, Li S, Han GL et al. Correlation Between Cephalometric Measures and End-of-Treatment Facial Attractiveness. J Craniofac Surg. 2016; 27: 405-9.

3. Cunningham SJ, Feinmann C. Psychological assessment of patients requesting orthognathic surgery and the relevance of body dysmorphic disorder. Brit J Orthod. 1998; 25: 293-8.

4. Pavoni C, Gazzani F, Franchi L, Loberto S, Lione R, Cozza P. Soft tissue facial profile in Class III malocclusion: long-term post-pubertal effects produced by the Face Mask Protocol. Eur J Orthod. 2019; 41: 531-6.

5. Liu Z, McGrath C, Hägg U. The impact of malocclusion/orthodontic treatment need on the quality of life: a systematic review. Angle Orthod. 2009; 79: 585-91.

6. Cacciatore G, Ugolini A, Sforza C, Gbinigie O, Plüddemann A. Long-term effects of functional appliances in treated versus untreated patients with Class II malocclusion: A systematic review and meta-analysis. PloS one. 2019; 14.

7. Proffit WR, Fields HW. Contemporary orthodontics. St. Louis: Mosby. 2013: 220-75.

8. Kocadereli I. Changes in soft tissue profile after orthodontic treatment with and without extractions. Am J Ortod Dentofacial Orthop. 2002; 122: 67-72.

9. Basciftci A, Uysal F, Buyukurkmen A, Demir A. The influence of extraction treatment on Holdaway soft-tissue measurements. Angle Orthod. 2004; 74: 167-73.

10. Hoi-Jeong L, Kwang-Taek Ko K, Hyeon-Shik H. Esthetic impact of premolar extraction and nonextraction treatments on Korean borderline patients. Am J Ortod Dentofacial Orthop. 2008; 133: 524-31.

11. Solem RC, Marasco R, Guiterrez-Polido L, Nielsen I, Kim SH, Nelson G. Three-dimensional soft-tissue and hard-tissue changes in the treatment of bimaxillary protrusion. Am J Ortod Dentofacial Orthop. 2013; 144: 218-28.

12. Devereux L, Moles D, Cunningham SJ, McKNight M. How important are lateral cephalometric radiographs in orthodontic treatment planning. Am J Ortod Dentofacial Orthop. 2011; 139: e175-81. 
13. Zecca PA, Fastuca R. Berreta M, Caprioglio A, Macchi A. Correlation assessment between threedimensional facial soft tissue scan and lateral cephalometric radiography in orthodontic diagnosis. Inter J Dentistry. 2016.

14. Moshkelgosha V, Fathinejad S, Pakizeh Z, Shamsa M, Golhari A. Photographic facial soft tissue analysis by means of linear and angular measurements in an adolescent persian population. Open dentistry J. 2015; 9: 346.

15. Little RM. The irregularity index: a quantitative score of mandibular anterior alignment. Am J Orthod 1975; 68: 554-63.

16. Baccetti T, Franchi L, McNamara Jr JA. The cervical vertebral maturation (CVM] method for the assessment of optimal treatment timing in dentofacial orthopedics. Sem Orthod. WB Saunders. $2005 ; 11$.

17. Czarnecki ST, Nanda RS, Currier GF. Perceptions of a balanced facial profile. Am J Ortod Dentofacial Orthop. 1993; 104; 180-7.

18. Naini FB, Donaldson ANA, McDonald F, Cobourne MT. Assessing the influence of chin prominence on perceived attractiveness in the orthognathic patient, clinician and layperson. Int $\mathrm{J}$ Oral Maxillofac Surg. 2012; 41: 839-46.

19. Lines PA, Lines RR, Lines CA. Profilemetrics and facial esthetics. Am J Ortod Dentofacial Orthop. 1978; 73: 648-57.

20. do Rego MV, Martinez EF, Coelho RM, Leal LM, Thiesen G. Perception of changes in soft-tissue profile after Herbst appliance treatment of Class II Division 1 malocclusion. Am J Ortod Dentofacial Orthop. 2017; 151: 559-64.

21. Bergman RT. Cephalometric soft tissue facial analysis. Am J Ortod Dentofacial Orthop 1999; 116 : 373-89.

22. Iared W, da Silva EM, lared W, Macedo CR. Esthetic perception of changes in facial profile resulting from orthodontic treatment with extraction of premolars: a systematic review. J Am Dent Assoc. 2017; 148: 9-16.

23. Deen E, Woods MG. Rotational effects of Class II Division 1 treatment with the Herbst appliance and fixed appliances in growing subjects with different vertical patterns. J World Fed Orthod. 2019; 8: 18-23.

24. Pancherz $\mathrm{H}$, Anehus-Pancherz M. Facial profile changes during and after Herbst appliance treatment. Eur J Orthod. 1994; 16: 275-86.

25. Moseling KP, Woods MG. Lip curve changes in females with premolar extraction or nonextraction treatment. Angle Orthod. 2004; 74: 51-62.

26. Lin PT, Woods MG. Lip curve changes in males with premolar extraction or nonextraction treatment. Aust Orthod J. 2004; 21: 71-86.

27. Sarver DM. The importance of incisor positioning in the esthetic smile: the smile arc. Am J Ortod Dentofacial Orthop. 2001; 120: 98-111. 
28. Pişiren AB, Arman-Özçırpıcı A, Tunçer NI. Assessing the influence of chin prominence on profile esthetics: A survey study. J Cranio-Maxillofac Surg. 2018; 46: 628-34.

29. Modarai F, Donaldson JC, Naini FB. The influence of lower lip position on the perceived attractiveness of chin prominence. Angle Orthod. 2013; 83: 795-800.

30. Rathod AB, Araujo E, Vaden LJ, Behrents RG, Oliver DR. Extraction vs no treatment: Long-term facial profile changes. Am J Ortod Dentofacial Orthop. 2015; 147: 596-603.

31. Batwa W. The Influence of the Smile on the Perceived Facial Type Esthetics. BioMed Res Inter 2018.

32. Demir A, Uyusal T, Sari Z, Basciftci FA. Effects of camouflage treatment on dentofacial structures in Class II division 1 mandibular retrognathic patients. Eur J Orthod. 2005; 27: 524-31.

33. Godt A, Müller A, Kalwitzki M, Göz G. Angles of facial convexity in different skeletal Classes. Eur J Orthod. 2007; 29: 648-53.

34. Bokas J, Collett T. Effect of upper premolar extractions on the position of the upper lip," Aust Orthod J. 2006; 22; 31-7.

\section{Figures}

a)

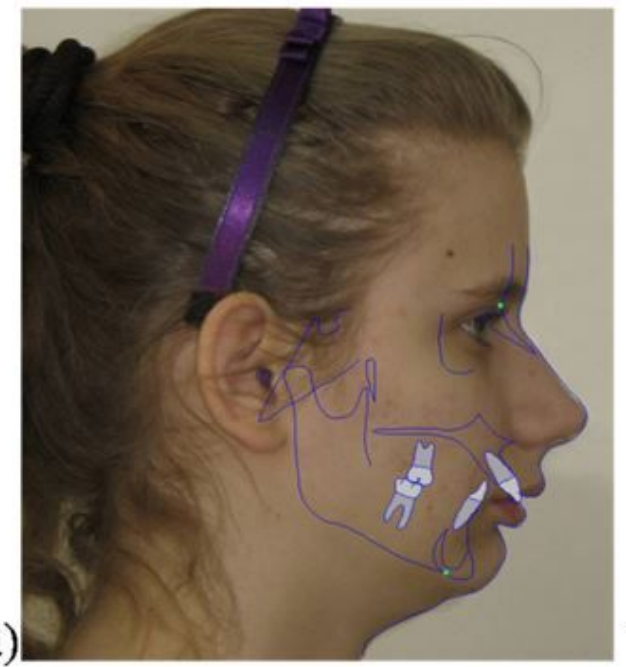

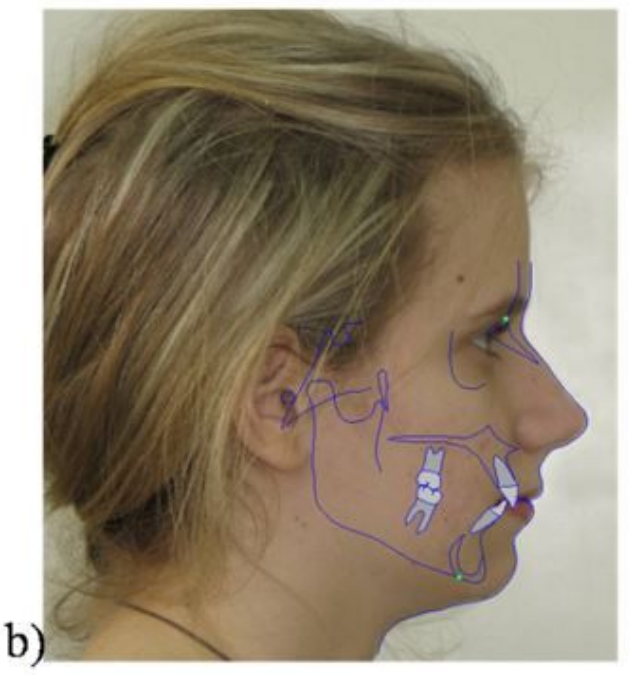

c)

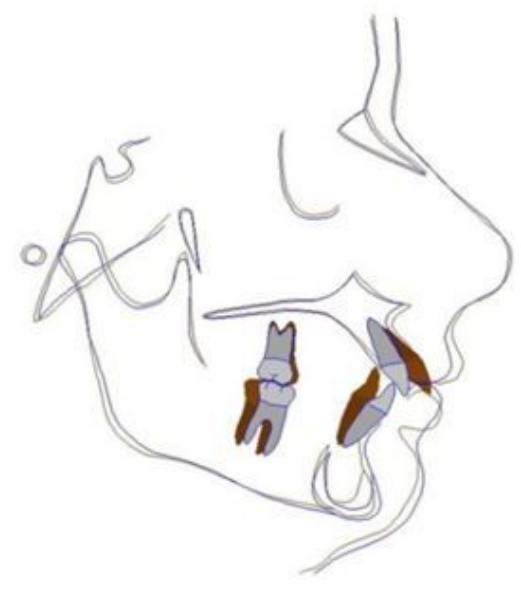

\section{Figure 1}

Non-extraction case. Superimposition of the cephalometric drawing to the patient's profile: a) before treatment, b) after treatment, c) superimposition of the cephalometric drawings before (brown) and after (gray) treatment with visible changes of the soft tissue profile. 
a)

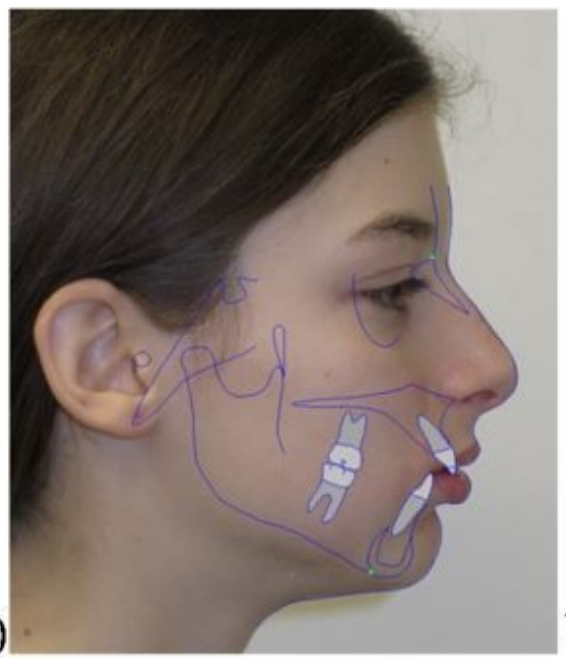

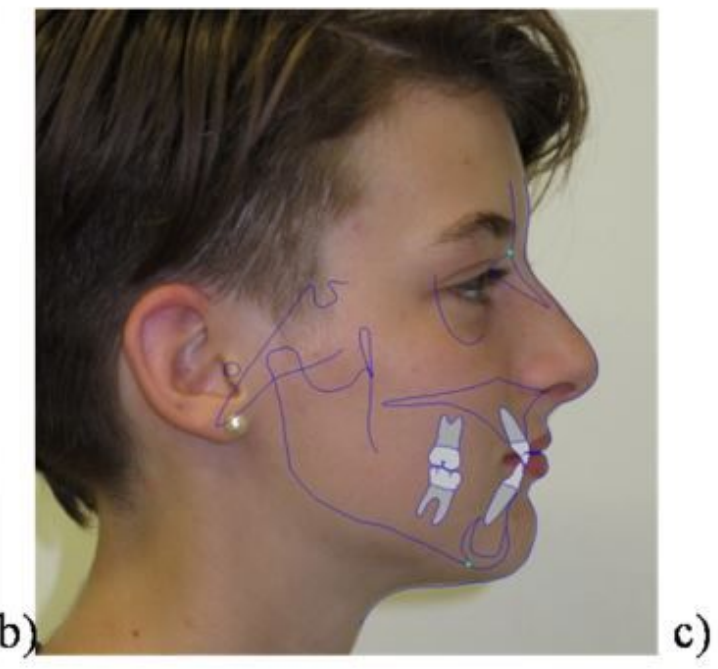

c)

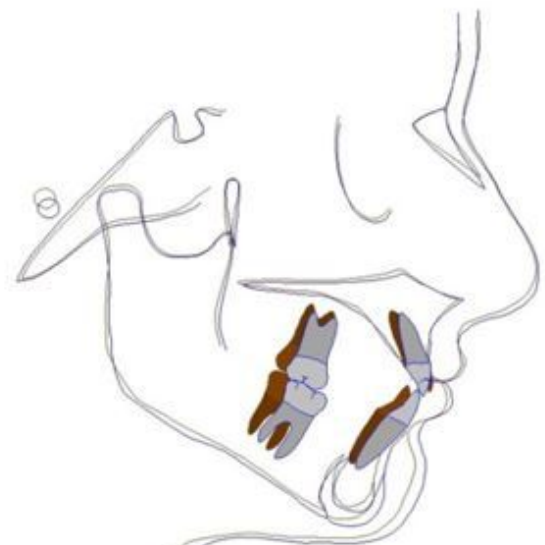

\section{Figure 2}

Extraction case. Superimposition of the cephalometric drawings to the patient's profile: a) before treatment, b) after treatment, c) superimposition of the cephalometric drawings before (brown) and after (gray) treatment with visible changes of the soft tissue profile.
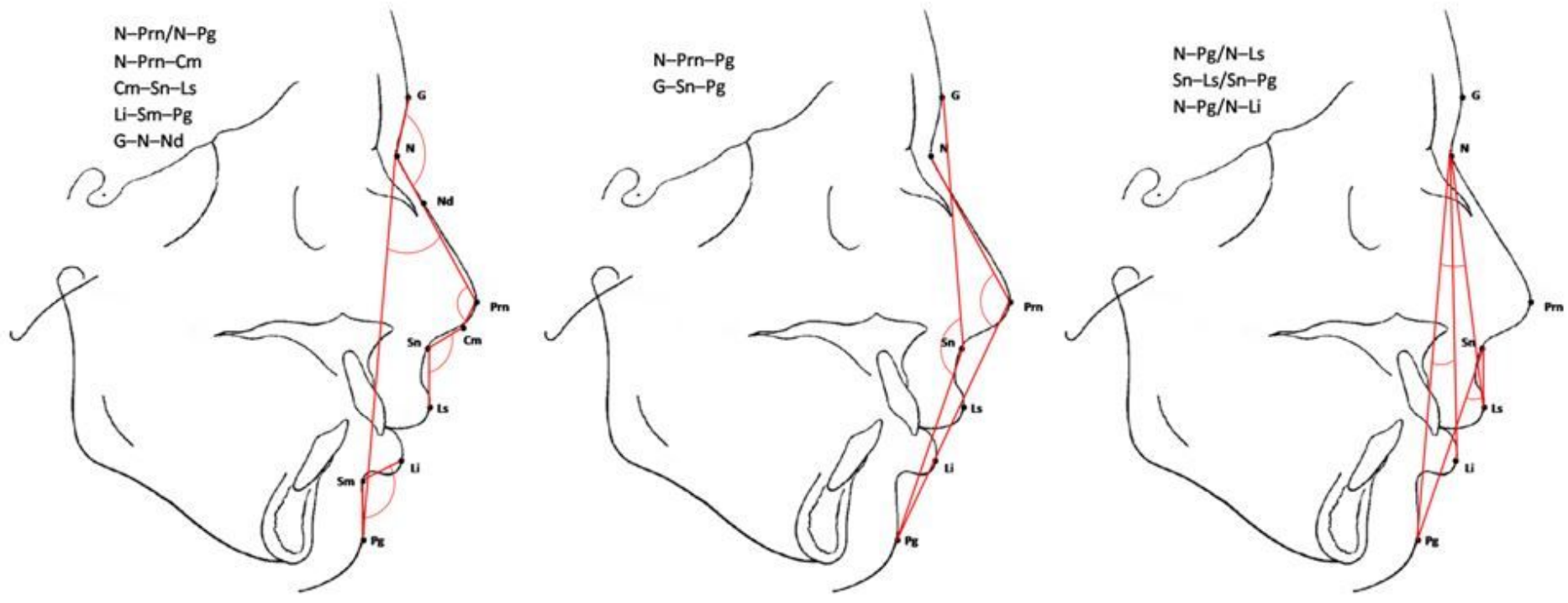

Figure 3

Soft tissue profile landmarks and angular parameters. 